\title{
2020 Market Analysis for 3rd Global Expo on Cancer and Oncology Research
}

\section{Michael R}

\author{
Research Associate, EH - Molecular+Integrative Phys Sci Prog, Harvard T.H. Chan School of Public Health, 665 Huntington \\ Ave Boston, E-mail: michael.retsky@gmail.com
}

To discuss the recent trends within the world, we are ecstatic in organizing the "3rd Global Expo on Cancer and Oncology Research" (Cancer Summit 2020) which is on the brink of be held during April 16-17, 2020 at Tokyo, Japan round the theme of "Deliberating world Wide cancer and Oncology Research".

The global cancer therapy market was valued at USD $136,254.35$ million in 2018 , and is estimated to be valued at USD 220,701.26 million in 2024, witnessing a CAGR of $8.37 \%$. Certain factors that are driving the market growth include increasing Patient Assistance Programs (PAPs), increasing government initiatives for cancer awareness, rising prevalence of cancer worldwide, and powerful R\&D initiatives from key players. Cancer therapeutics involves the utilization and administration of chemotherapy and oncology drugs to treat cancer. Worldwide cancer affects quite 10 million people annually and thus the incidence of cancer is predicted to extend by $2.4 \%$ annually to realize 14 million once a year by 2020 . Cancer is that the second commonest death within the industrialized world.

The target therapy segment is predicted to means absolutely the best CAGR of $9.68 \%$ during the forecast period. The target therapy includes hormone therapies, phenomenon modulators, apoptosis inducers, angiogenesis inhibitors, immunotherapies, signal transduction inhibitors, and toxin delivery molecules. Targeted therapy is attaining importance due to its specificity toward cancer cells, while sparing the toxicity to off-target cells. Quite 45 million Americans don't have insurance and millions more are underinsured; eight out of 10 uninsured people are from working families. Among those with insurance, one out of ten people, sixty five years previous or younger, and one in 3 persons over sixty five years do not have medicine coverage.

The carcinoma segment is believed to account for the foremost important market size over the forecast period. This is often majorly attributed to the upper and continuously increasing prevalence of carcinoma across the world. As per estimates provided by the carcinoma Organization in 2018, it's estimated that over 2,66,120 new cases of invasive carcinoma are expected to be diagnosed in women within the us, in conjunction with 63,960 new cases of non-invasive (in situ) carcinoma . North America currently dominates the marketplace for cancer therapy and is predicted to continue its stronghold for a couple of years. This region is predicted to extend its market share within the long run, because of the increased adoption of cancer therapy. US holds majority of the market within the North American region, due to the rising prevalence of cancer within the country. Consistent with the National Cancer Institute (NCI), in 2016, 1.6 million people suffered from cancer, and around 0.5 million people died from cancer. This figure indicates that the prevalence of cancer is rapidly increasing within the US.
Hence, Patients help Programs (PAPs) have emerged during an effort to help patients United Nations agency are lacking insurance or prescription coverage get the medication they need . These programs area unit provided by pharmaceutical firms to supply free or affordable prescription drugs to patients World Health Organization area unit suffering from serious sicknesses. Several big pharmaceutical companies, like Pfizer and Eli lily, have also started these programs to assist uninsured patients who are affected by chronic diseases. Thus, an oversized range of uninsurable patients, suffering from cancer, can also bare cancer therapies that are likely to strengthen the expansion of the market.

\section{Cancer Hospitals Graph}

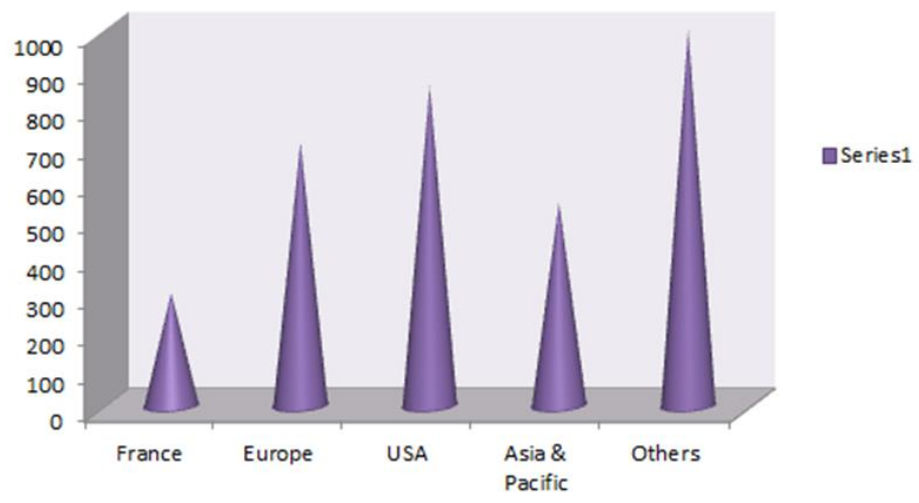

For further queries please

\section{Contact us}

Mercedes Odgen

WhatsApp No: +44-7426-058710

Website: http://cancersummit.alliedacademies.com/ 